\title{
PAISAJE, CONMEMORACIÓN EMBLEMÁTICA, E IDENTIDAD: LA PAMPA DE AYACUCHO, COMO "GEOGRAFÍ́A DE LA MEMORIA"
}

\author{
LANDSCAPE, EMBLEMATIC COMMEMORATION, AND IDENTITY: \\ THE PAMPA DE AYACUCHO, AS A "GEOGRAPHY OF MEMORY"
}

Juan José Oré Medina ${ }^{1 *}$, José María Vásquez Gonzales ${ }^{1}$

juan.ore@unsch.edu.pe; jose.vasquez@unsch.edu.pe

${ }^{1}$ Universidad Nacional de San Cristóbal de Huamanga, Ayacucho, Perú

\author{
*Correspondencia: Juan José Oré Medina. Email: juan.ore@unsch.edu.pe
}

Recibido: 05.03.21 | Aprobado: 25.04.21

\section{RESUMEN}

El artículo reflexiona, desde una perspectiva geográfica, el paisaje de la Pampa de Ayacucho, como lugar de conmemoración emblemática. Estudia a la vez, las razones políticas del porque el Estado peruano, la "comunidad de notables" de Ayacucho, tuvo la decisión de dónde y cómo ubicar el Obelisco en homenaje a los vencedores de la Batalla de Ayacucho de 1824. Finalmente, se plantea las relaciones entre "geografía y lugar de memoria" e identidad, incidiendo de como la sociedad ayacuchana, participa de los rituales, ceremonias cívicas, anualmente; considerando tanto el espacio y al monumento, como prácticas culturales y simbólicas que les inculcan el sentimiento de adhesión y lealtad hacia sus "héroes" nacionales.

Palabras clave: Geografía de la memoria, identidad, conmemoración, pampa de Ayacucho, paisaje emblemático.

\begin{abstract}
The article reflects, from a geographic perspective, the emblematic commemoration landscape of the Pampa of Ayacucho, as place. Go into at the same time, the political reasons of the because the Peruvian Estado, the good marks community of Ayacucho, it had decision from where and how to locate the Obelisco in homage to the conquerors of Ayacucho's battle of 1824. Finally, the relations among geography and room are presented by heart and identity, affecting of as the society ayacuchana, notify of the rituals, civic ceremonies, annually; Considering point the space and to the monument, as cultural and symbolic practices that they inculcate them the adhesion sentiment and loyalty toward his national heroes to.
\end{abstract}

Keywords: the memory's Geography, identity, commemoration, Ayacucho's pampa, emblematic landscape. 


\section{INTRODUCCIÓN}

Reflexionar sobre los hitos históricos sucedidos en la región de Ayacucho, nos conlleva a recordar los grandes acontecimientos que se sucedieron en el tiempo pasado, los cuales nos llevan a realizar una (re)memoración de dichos sucesos, en vísperas del bicentenario de la batalla de Ayacucho de 1824, donde se logró la ansiada Independencia del Perú y la libertad hispanoamericana.

Es este contexto histórico regional, que vamos a desgranar durante el presente artículo; para describir, explicar y comprender, la importancia que tiene el paisaje emblemático de la Pampa de Ayacucho, como "geografía de la memoria", donde se realizan anualmente ceremonias conmemorativas a los "Vencedores" de dicha batalla, considerados como parte de nuestra identidad nacional.

\section{“GEOGRAFÍA Y LUGAR DE MEMORIA” EN AYACUCHO.}

El concepto de "lugar de memoria" ha sido trabajo por el francés Pierre Nora, que lo define como "el conjunto de lugares donde se ancla, condensa, cristaliza, refugia y expresa la memoria colectiva, la noción se extendería a "toda unidad significativa, de orden material o ideal, de la cual la voluntad de los hombres o el trabajo memorial de cualquier comunidad". Es decir, no es cualquier lugar el que se recuerda, sino aquel donde la memoria actúa; no es la tradición, sino su laboratorio. Por ello, lo que hace del lugar un lugar de memoria es tanto su condición de encrucijada donde se cortan diferentes caminos de la memoria como su capacidad para perdurar y ser incesantemente remodelado, (re) abordado y revisitado. Un lugar de memoria abandonado no es, en el mejor de los casos, sino el recuerdo de un lugar (Allier, 2008, pp. 166-167).

Entonces, la pampa de Ayacucho no es cualquier lugar, sino un espacio emblemático que se recuerda, porque fue en dicho lugar donde se llevó a cabo la épica jornada de la batalla de Ayacucho en 1824; recordada, por toda la nación peruana, por fue el lugar donde se selló la libertad hispanoamericana. Por otro lado, consideramos, como dice Eugenia Allier Montaño, "la pareja lugar-medio. La definición fue aportada por Cicerón: el lugar, locus, es el emplazamiento (los cuartos de una casa o sus columnas) donde el orador es invitado a colocar las imágenes de las cosas que quiere retener, recomendándosele elegir imágenes vivas. (Allier, 2008, p.189). En ese sentido, el paisaje de la pampa de Ayacucho no sólo es un "lugar de memoria" sino lugar donde no sólo se va a recordar la épica batalla y homenajear a sus "héroes" sino es un lugar en constante reconstrucción anualmente por los miembros de la comunidad de notables de Ayacucho (presidente del Gobierno Regional, prefectos, alcaldes, gobernadores distritales, sacerdotes, intelectuales, periodistas, comerciantes, pobladores en general, etc).

Asimismo, definimos la "geografía de la memoria", como la que "localiza la historia y sus representaciones en el espacio y el paisaje. Contesta a la cuestión de dónde está la memoria, en términos de lugares y sitios que vacían una cierta visión de la historia en un molde de permanencia conmemorativa" (García, 2009, p. 183). La pampa de Ayacucho, entonces, es convierte en el lugar específico, donde la "geografía de la memoria", localiza anualmente su representación, a través de ceremonias cívicas, escenificaciones, rituales, desfiles y espectáculos de celebración emblemática. En conclusión, cada 9 de diciembre, de cada año, la "geografía y lugar de memoria", como es la pampa de Ayacucho, es el 
momento propicio para que el Estado y las instituciones públicas y privadas, realicen la rememoración de la batalla de Ayacucho de 1824, se hace uso político de la memoria.

\section{DEFINIENDO A LA HISTÓRICA PAMPA DE AYACUCHO}

Existes muchas discrepancias sobre la pampa de Ayacucho. La costumbre de un pueblo es algo que no se puede evitar; pero, si se puede educar. Por lo tanto, es necesario conocer algo sobre el paisaje de Ayacucho, conocido como pampa.

El año 2006, escribimos sobre el tema, manifestando que no existía y no existe la denominación de "Pampa de Quinua", manifestando en ese entonces (2006), que el nombre de "Quinua" se refería al pueblo que se ubica muy debajo de la histórica pampa donde se llevó a cabo la batalla de Ayacucho en 1824. Desde ese momento, muchos profesionales y autoridades iniciaron a llamarle con el verdadero de Pampa o Llano de Ayacucho" (Vásquez, 2006).

Se debe tener en cuenta que en las alturas que dominan al pueblo de Quinua estaban ocupadas por indios, que tuvieron la osadía de aproximarse hasta media milla del campamento de los patriotas que se encontraban en la pampa y que habían quitado a una partida de dragones varias cabezas de ganado (Vargas, 1974, p. 82). Dicho Llano, desde la visión geográfica, tendrá de ancho, desde la altura pendiente del Condorcunca extendiéndose hasta el pueblo del pueblo de Quinua, 500 toesas (medida antigua francesa equivalente a un metro $945 \mathrm{~mm}$ ) y 800 de largo de quebrada a quebrada, norte a sur (Vargas, 1974, p. 70). La pampa es abrupta, pedregoso, con pequeños arbustos para 1974 y con una pendiente de 40 grados.

Según el Monseñor Fidel Oliva Escudero, la llamada Pampa de Ayacucho tiene escasamente 5 kilómetros de perímetro, sobre el terreno en que se batieron más de 15,000 hombres (Oliva, 1924, pp. 27-28). Para el Ing. José Ruiz Fowler, "este campo se extiende desde el pueblo de Quinua hacia el pie de la expresada montaña o cerro Condorcunca de Este a Oeste. Su extensión es casi de una legua cuadrada; a sus extremos de Sur a Norte cortados por quebradas profundas y otros barrancos también la atraviesa de $\mathrm{S}$ a N., dejando este último un barranco de más de 200 metros de largo y 10 metros de altura; este barranco está frente al Condorcunca. Las quebradas de los extremos son tan profundas que se hace imposible escalarlas; estando la de la izquierda llena de monte de chachacomas (Stereoxilón), quinuar (Polylepís racemosa) y espinos como la chuquiragua espinosa y otras más; por otra parte, lo rocalloso de estos sitios darán una idea de su difícil acceso.

Los realistas en vista del terreno dispusieron que Valdez con la vanguardia, 4 piezas de artillería y dos escuadrones de Fernando VII, rompiesen el movimiento ofensivo 'por la derecha, para enseguida forzar el flanco izquierdo de los patriotas (Ruiz, 1924, p. 120).

Todos coinciden en que la pampa de Ayacucho era un paisaje de difícil acceso y de quebradas que podían hacer que cualquier ejército sucumba en dicho espacio abierto. Pero en la memoria de muchos autores, también se manifestaba que a la vista era un lugar hermoso, donde se miraba a los "cerros desnudos, grises con tintes amarillentos y rojizos. Por lo tanto, era un monumento natural dedicado a la gloria de América” Dammert, 1974, p. 162). La pampa está a una altura de 3,400 msnm. Declarado Patrimonio Histórico, por 
resolución suprema $\mathrm{N}^{\circ}$ 709-73-ED de fecha 23 febrero de 1973 y reafirmada con D.S. $\mathrm{N}^{\circ}$ 119-80 AA del 14 de agosto de 1980, sea considerada como Santuario Histórico Nacional (Vásquez, 2006, p.22).

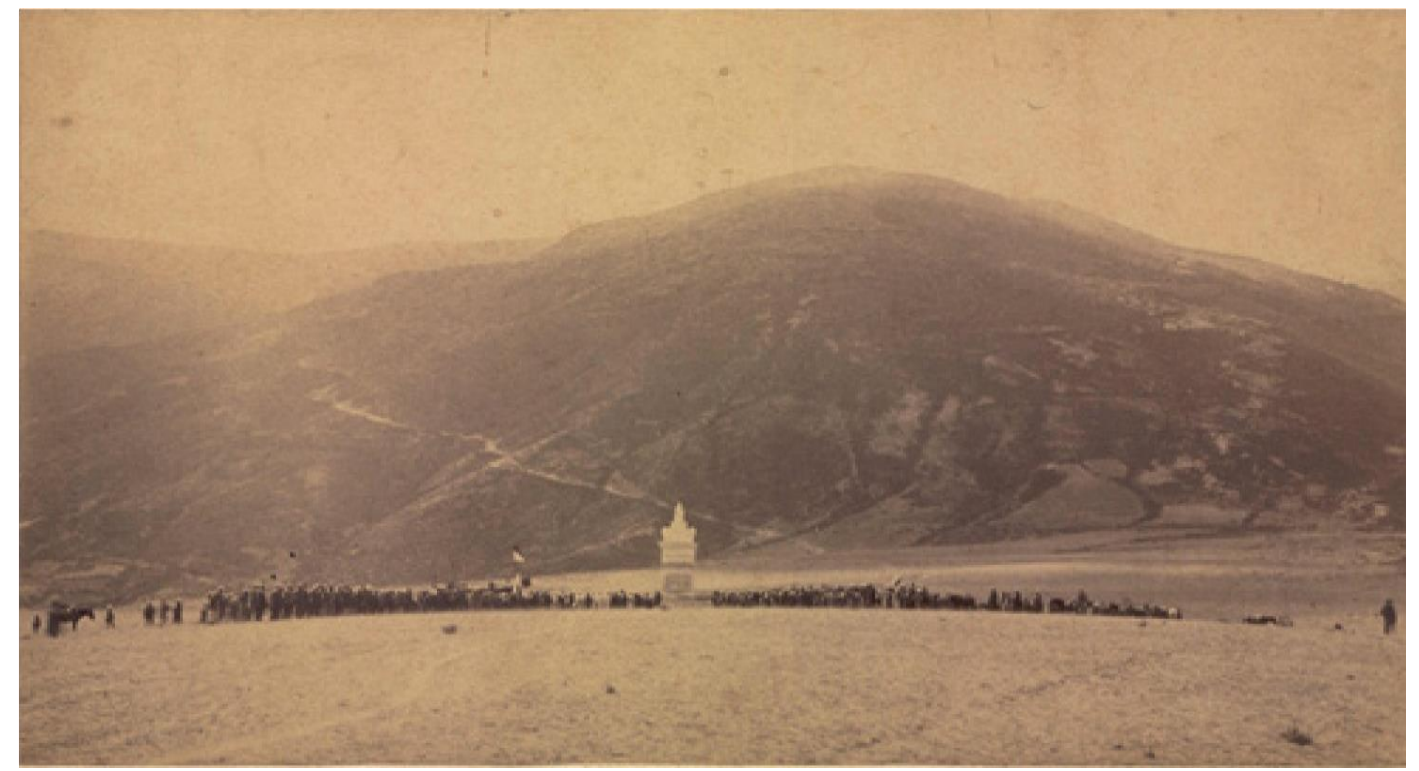

Vista panorámica del Santuario Histórico Nacional de la Pampa de Ayacucho. En la pampa se ubica el monumento conmemorativo a la Libertad, en homenaje a la Batalla del 9 de diciembre de 1824. A sus costados, militares y civiles en la ceremonia cívica patriótica del 9 de diciembre de 1924. Al fondo, se divisa el emblemático cerro Condorcunca.

\section{USOS POLÍTICOS DE MEMORIA: ¿CÓMO SE ELIGIÓ EL LUGAR DE LA PAMPA DE AYACUCHO?}

Son algunas interrogantes que nos haremos para luego responderlas, como ¿Por qué se eligió la pampa como lugar de la batalla el 9 de diciembre de 1824? ¿Acaso no existía otro lugar más estratégico para llevarse a cabo la batalla de Ayacucho? ¿Acaso la pampa era un lugar táctico y estratégico para Antonio José de Sucre, jefe del Ejército Unido Libertador?

Según, Rodrigo Gutiérrez Viñuales, la decisión de dónde y cómo colocar los monumentos fue uno de los motivos de debate más interesantes en el proceso conmemorativo y urbano. El comentario de Schiaffino era traído a cuento para justificar su propuesta acerca de que la estatua de Belgrano fuera colocada en la avenida de mayo, mirando a la Plaza. "El pedestal no ocuparía mayor espacio que un refugio, la estatua tendría las condiciones de encierro que necesita y teniendo la vista desde cualquiera de los extremos de aquella calle se vería en escorzo; un testimonio mucho más contemporáneo, de 1937 y en Cuba, señalaba que el monumento, por regla general, era emplazado "en el centro geométrico de una manzana destinada a parque o plaza pública, y es natural que así ocurra, pues las personas que intervienen no conciben que en una manzana pueda situarse un monumento en otro lugar más que en su centro geométrico. Cuando esta regla no se cumple se sitúa en una esquina o en una isleta en la intersección de dos calles, como si se tratara de inmortalizar a un fiel policía de tránsito". Los debates y análisis en torno al destino final de la misma generaron largas páginas y memorias presentadas por las direcciones de urbanismo, comisiones y subcomisiones, municipalidad, etc., hasta dar con 
el emplazamiento definitivo. En resumidas cuentas, la importancia del lugar de emplazamiento como "sitio" conmemorativo y su relación con el espacio público, son condiciones atacadas en forma permanente y sin piedad a lo largo de la historia contemporánea, especialmente con dicha rotación de monumentos (Gutiérrez, 2008, pp. 33-35).

Para el caso de la pampa de Ayacucho, es necesario conocer que sí Antonio José Sucre, escogió dicho lugar, fue porque lo considero estratégico y táctico para llevar a cabo dicha batalla del 9 de diciembre de 1824. Veamos el porqué de dicha decisión:

1. Apreciamos que al igual que todos los autores consultados, la selección del terreno del Llano de Ayacucho fue determinante. Luego de haber releído numerosas veces las memorias, los relatos, los mapas y fotos del campo de Ayacucho, puntualizamos dos observaciones bien marcadas. La pendiente pronunciada de las faldas del Condorcunca y la presencia de las "lloclla" o mal llamado huaico dificultaron los movimientos y cortaron perpendicularmente los ejes de avance de ambos bandos, determinando que los tiempos de descenso de las divisiones realistas excedieran las previsiones.

2. Las unidades reales (vanguardias de la división) que lograban sortear la lloclla, fueron batidas al instante por los independientes, aprovechando esta momentánea superioridad local. Al releer la dificultad que el terreno ocasionó a la maniobra, uno no toma conciencia hasta que el señor coronel peruano Carlos Dellepiane, lo revive en la batalla misma, como un protagonista más. Por esto mismo, una batalla que dio oficialmente inicio a las 10 am del 9 de diciembre de 1824, quizás no habría debido lanzarse sino hasta que las divisiones Villalobos y Monet hayan completado su descenso.

Vemos claramente que el coronel Dellepiane, que la masa de la artillería realista que quedó a retaguardia del general Villalobos no había sido armada y puesta en posición. También destaca que algunos escuadrones lograron descender completos o fueron de los primeros en descender y lógicamente, los caballos fueron bajados del tiro. Los que montañeses saben que descender montado no siempre resulta lo más cómodo y práctico en estas pendientes. A continuación, se concluye que las divisiones reales tuvieron que afrontar el descenso de un sistema de laderas de inclinación pronunciada sobre las faldas del Condorcunca, si bien estas no superan los 300 metros. Entonces, se observa que la fase 1, prevista proel Virrey La Serna, era una operación de extrema complejidad y que estar desplazándose en el orden de los 7,000 hombres necesitaba de un control de los movimientos muy estricto y quizás de un sistema de ayudantes acaballo como el que dispusiera el General San Martín en Paipú. Por el contrario, se lee que el Virrey y Villalobos descendieron "a pie" en paralelo con las divisiones.

3. El General Sucre, explota hábilmente los minutos que demoran los batallones de infantería realista en cruzar la lloclla al quedar expuestos al término de esta maniobra: Primero, los realistas como batidos por la división del General José María Córdoba ante la imprudencia del jefe del Batallón "Vanguardia" (Coronel Rubín de Celis) y luego en el centro (División Monet) emplea al escuadrón de Granaderos a 
caballo y a los Húsares de Junín para atacarlos por los flancos y al batallón colombiano "Vargas", por el frente de la lloclla.

4. Exitismo que se apodero del ejército realista, que le jugó en contra. Porque no permitió detectar las verdaderas limitaciones que imponía el llano; es decir, desde el sector amesetado (sic) del Condorcunca y a la vista del dispositivo colombiano se planificó el ataque real. Se trazaron ataques y coordinaciones de divisiones, pero, no se tomó conciencia del encajonado que resultaría el ataque con grandes formaciones de infantería sin poder maniobrar, excepto frontalmente. No se había previsto un plan de contingencia, si la batalla se perdía. La tropa había dejado sus mochilas y bagajes en beneficio de la comodidad en el combate. Se pensó erróneamente que repitiendo la fórmula de atacar sobre la pendiente descendiente; es decir, "a valle", era una solución que aportaba éxito, cuestión que quedó derogada a poco de iniciarse el ataque de la división Villalobos. Cuando la bandera colombiana flameó en la falda del Coindorcunca, el exitismo se volvió en contra.

Se concluye, entonces, que la pampa de Ayacucho fue un lugar táctico y estratégico para el Ejército Unido Libertador, dirigidos por el General Antonio José de Sucre, que ya lo había estudiado la noche anterior a la jornada y es por eso que se ubicó en la planicie; esperando que el ejército realista se coloque en la cima del Condorcunca y así lo hizo; porque este ejército despreció y fue aprovechado por Sucre. El exitismo deliberado en el Virrey La Serna y su sistema de comando, provocó una profunda desazón en la masa del ejército, porque quedó demostrado que era un castillo de naipes que se desmoronó a las pocas horas de dar inicio al ataque de la División Villalobos.

En el marco estratégico, la magna victoria de Ayacucho marca el fin de la dominación española en América del Sur. Sin lugar a duda, la empresa que se iniciara con el General José de San Martín tuvo su coronación en la histórica pampa de Ayacucho. Es importante advertir, que el paisaje histórico de la pampa de Ayacucho se convirtió en el lugar táctico y estratégico para Antonio José de Sucre que logró el triunfo porque nunca despreció el terreno y más bien lo estudio y lo puso a prueba el 9 de diciembre, dándole como resultado la victoria final.

\section{LA PAMPA DE AYACUCHO COMO “GEOGRAFÍA DE LA MEMORIA" Y PAISAJE EMBLEMÁTICO DE IDENTIDAD}

La relación que existe entre memoria y el espacio geográfico es básico para comprender, la "geografía de la memoria"; donde los geógrafos interesados por la geografía política y geografía cultural insertaron en sus estudios las dimensiones espaciales de la memoria, concentrándose en los lugares y paisajes, donde se dieron acontecimientos históricos que la sociedad debería recordar y no olvidar. En este marco geográfico, se inserta la pampa de Ayacucho como "geografía de memoria".

La "geografía de memoria", se refiere específicamente a los paisajes, espacios y sitios, donde la comunidad asiste a rendir homenaje a un acontecimiento o personajes que hicieron historia a través del tiempo. En este sentido, la "geografía de memoria" se centra en la pampa de Ayacucho donde sus "héroes" lograron la libertad de América del Sur. Entonces, el lugar que ocupa la "geografía de memoria", es comprender la importancia 
que toman los campos, terrenos, llanos o pampas en un determinado momento donde se realizan batallas, como la de Ayacucho; en ese sentido, la pampa de Ayacucho toma relevancia por ser lugar estratégico y táctico. Aquí, entonces, se impone el tiempo y espacio que se debe tener en cuenta en los estudios geográficos e históricos, porque ambas disciplinas se complementan en todo momento y eso muy lo saben geógrafos e historiadores. El papel que cumple la disciplina geográfica y, en especial, la escuela vidaliana han desempeñado un gran papel en la construcción de la conciencia nacional no sólo a la idea de nación sino de "lugares de memoria", como la pampa de Ayacucho lo es. "Maurice Halbwaches, presta una considerable atención a los modos en que la memoria colectiva se constituye espacialmente mediante su anclaje en ciertos lugares materiales (García, 2009, p. 180).

La "geografía de memoria" sobre la pampa de Ayacucho, considerada como lugar emblemático desde el punto de vista geográfico, es de relevante imaginación popular, de toponimia urbano-rural; de paisajes y representaciones de la estrecha conexión entre la sociedad y el medio, como, en particular, los relacionados con el mundo rural; entonces, el interés geográfico de la "memoria" nos proporciona la importancia que tienen el Santuario Histórico Nacional de la Pampa de Ayacucho para el Estado peruano y la comunidad de notables de la sociedad ayacuchana en vísperas del Bicentenario de la Batalla de Ayacucho para el año 2024.

La "geografía de memoria", profundiza, sobre todo, en el estudio de los sitios materiales donde la relación entre lugar y memoria es más evidente, el caso de la pampa de Ayacucho, teniendo en cuenta, los ceremoniales de la memoria; es decir, rituales, escenificaciones, desfiles, discursos, espectáculos, celebraciones, etc. que se dan en la misma pampa.

Como dice Jacobo García Álvarez, “es verdad que las incursiones geográficas en las dimensiones simbólicas del espacio, e incluso en el papel desempeñado por ciertos lugares y paisajes en los procesos de construcción nacional, son anteriores. Desde la aparición de la geografía humanística de las décadas de 1970 y la revitalización de la geografía regional y política a partir de los $80(\mathrm{XX})$ el análisis de tales cuestiones figuraba en la agenda de trabajo de la disciplina" (García, 2009, p. 184).

Más aún, en la geografía regional de Ayacucho, como hemos visto, líneas arriba, intelectuales como Fidel Oliva Escudero, Pio Máx Medina, Manuel Jesús Pozo y el Ing. José Ruiz Fowler, inciden en insertar la geografía como un elemento básico para comprender la historia regional, siendo esto fundamental para que la disciplina se convierta en este nuevo siglo XXI en "geografía de memoria" donde los lugares son considerados emblemáticos, según, su aporte en la geografía regional de Ayacucho.

El Santuario Histórico Nacional de la Pampa de Ayacucho, se convierte en un paisaje simbólico y emblemático, por haberse desarrollado ahí, la histórica batalla de Ayacucho en 1824; considerado como un "paisaje patriótico y cívico", donde la memoria colectiva de poblador ayacuchano no olvida, gracias a sus difusores; es decir, la comunidad de culto. Es este, paisaje emblemático, dentro de la "geografía de memoria", como es la pampa de Ayacucho, donde se atribuye la simbolización de la identidad nacional. 
La pampa de Ayacucho, dentro de la "geografía de memoria" explora la topografía patriótica de las que forman parte este paisaje y santuario nacional de valor identitario en la que suele integrarse el escenario de la batalla del 9 de diciembre de 1824. Por eso, la relación entre el paisaje, memoria histórica e identidad se ha centrado en la transformación del espacio de la pampa, donde en la actualidad, ya no sólo se "recuerda" a los vencedores de dicha batalla, sino que se ha convertido en un espacio donde se asiste y se participa consciente e inconscientemente-en las ceremonias cívico patrióticas que se dan en dicho "lugar de memoria". Entonces, tanto la pampa como el Obelisco, como monumentos de identidad, tienen como finalidad, inserta en la "memoria colectiva" de la sociedad, el nacionalismo que todo habitante del Perú y sobre todo, de Ayacucho, debe conservar. Por eso es que el uso de la "ornamentación simbólica de carácter institucional (banderas, enseñas, himno, obelisco, pampa, etc.); la manera de nombrar las calles, plazas y espacios públicos; el diseño urbanístico, etc.” (García, 2009, p.189), el nombre del propio llano; son considerados dentro de la "geografía de memoria".

Según, Johanna Hamann Mazuré, "el espacio urbano es, en principio, un dispositivo de componentes que estructuran la ciudad y que permite unos conjuntos de relaciones físicas, de movilidad, sociales y económicas. Se entiende por estructura todos aquellos elementos que le otorgan una configuración específica al asentamiento en el territorio a través del tiempo y en el espacio. Los espacios públicos son los espacios correspondientes al área urbana libre y de uso público, que constituyen un componente esencial en la estructura urbanística de todo barrio, de toda ciudad. Es en los espacios públicos donde reside la identidad particular de cada barrio, de la ciudad, y de sus habitantes. Son espacios creados para ser compartidos por la colectividad del lugar y se van configurando según de las características de las nuevas urbanizaciones, determinadas por su demografía y su geografía, siempre preexistente en una ciudad en crecimiento. Varían por su jerarquía, extensión, uso, y ubicación dentro de la ciudad. "La formación de parques, plazas y bosques es siempre plausible; deben proyectarse en forma compatible con las necesidades de cada barrio o zona de la ciudad'. En cuanto a la referencia de plazas y paseos, su significación varía también, por su ubicación estratégica y por su importancia como punto referencial dentro de la ciudad. La disposición dentro de la trama urbana es determinante, e incluso la forma del contorno arquitectónico y del barrio al que pertenece. De lo que no queda duda es que siendo el espacio público una herramienta de orden político, se le confiere, desde su origen, la cualidad de ser el dispositivo más antiguo para la construcción de conciencia cívica. Es a través de sus ritos y ceremonias colectivas que la comunidad se integra, intercambia y se moviliza” (Hamann, 2011, pp. 206-207).

Entonces, la pampa de Ayacucho, como parte esencial de todo un departamento como Ayacucho, se convierte en un elemento indispensable de la "geografía de memoria" como parte de la identidad juntamente con el Obelisco, que es la representación "viva" de sus héroes" que pelaron en dicha batalla de 1824 . 


\section{PASADO-PRESENTE DE LAS CONMEMORACIONES Y (RE)MEMORACIÓN SOBRE LA BATALLA DE 1824 EN LA HISTÓRICA PAMPA DE AYACUCHO.}

¿Qué significa conmemorar un pasado como la batalla de Ayacucho? ¿Cómo se recupera, se recuerda ese pasado histórico? A través de las conmemoraciones, la cual se ha transformado en un lugar de memoria, en espacio donde se revive dicho acontecimiento; la "conmemoración, en su forma clásica, podía apelar a la continuidad con el pasado, al ejercicio de una memoria colectiva (ilustrada y alimentada por la historia), a su distinción nítida con las memorias particulares (de grupos, individuos, de os vencidos, etc.) en una especie de celebración unitaria" (Rabotnikof, 2009. p. 191).

Desde que el Libertador Simón Bolívar, ordenó levantar una columna consagrada a la gloria de los vencedores en el mismo escenario donde se llevó a cabo la batalla; es decir, en la pampa de Ayacucho; y que en la cima de esta columna se colocará el busto del Benemérito General Antonio José de Sucre, y en ella se grabarán los nombres de los generales, jefes, oficiales y cuerpos en el orden y preeminencia que le corresponde. Hizo que con el correr del tiempo, dicha columna se haga realidad el 28 de julio de 1897, donde se levantó, gracias al prefecto Pedro Portillo; desde entonces, la Pampa de Ayacucho, se erigió como un "lugar de memoria",

Desde fines del siglo XIX, tanto la pampa como el monumento conmemorativo, se convirtieron en lugar y acto de conmemoración y de (re)memoración a sus héroes. Según, Pierre Nora, las conmemoraciones contemporáneas transformadas de ahora en adelante en "lugares de memoria". El Bicentenario no necesita exhibir sus títulos para representar la conmemoración (Nora, 2008, p. 168). Y como dice Eugenia Allier, la batalla de Ayacucho, "era una historia que daba la misma importancia a la conmemoración de un acontecimiento que al acontecimiento en sí mismo: al ponerlos en el mismo plano, se reducían "las realizaciones más resplandecientes de la historia y de la tradición nacionales y los más humildes instrumentos de fabricación de esta historia y de esta tradición". En ese sentido, se trataba de una historia que se interesa menos por los determinantes que por sus efectos; menos por las acciones memorizadas e incluso conmemoradas que por el rastro de estas acciones y por el juego de estas conmemoraciones; que se interesa menos por los acontecimientos en sí mismos que por su construcción en el tiempo, por su desaparición y por el resurgir de sus significaciones; menos por el pasado tal como ha acontecido que por su reutilización, sus malos usos, su impronta sobre los sucesivos presentes; menos por la tradición que por la manera en la que ha sido formulada y trasmitida. En síntesis, una historia que no es ni resurrección, ni reconstitución, ni reconstrucción, ni incluso representación, sino rememoración en el sentido más fuerte de la palabra. Una historia que no se interesa por la memoria como recuerdo, sino como economía general del pasado en el presente (Allier, 2008, p. 176). Ahora, la memoria ya no es transmitida de generación en generación como parte de un saber vivido, sino como huella, historia y selección (por ejemplo, a través de los lugares de memoria) (Allier, 2008, pp. 185-186).

Hablar de lugar, según David Díaz, "supone pensar, el territorio de la memoria como lugar construido se despliega al mismo tiempo en un sentido político. El lugar (de conmemoración y de remomeración), es hoy considerado como sitio de memoria donde 
el municipio asumió su dirección y la responsabilidad de la reconstrucción histórica, la búsqueda de justicia y la elaboración de propuestas participativas en torno a la reflexión sobre nuestro pasado, nuestro presente y sobre el futuro. Los sitios de memoria, con diferentes usos y significados con relación a los hechos en ellos ocurridos, constituyen valiosos testimonios de la historia de nuestro país. Este es un lugar que hoy refleja el encuentro y el protagonismo, que simboliza la memoria, la verdad y la justicia (Díaz, 2007).

La "geografía de memoria", no deben entenderse como meros receptáculos en donde la memoria se deposita y se cristaliza, sino como sitios que funcionan como disparadores de nuevos sentidos y reinterpretaciones, constituyéndose en lugares en los cuales la memoria se activa, se vuelve dinámica, se transforma, se torna reflexiva y productora de nuevos sentidos y de resignificaciones constantes. En ambos casos, la reapropiación y resignificación de los espacios marcados y seleccionados para convertirse tanto en lugares de memoria como en espacios memoriales se conectan. El lugar de memoria o el espacio memorial, en donde se realizan tareas específicas en torno a la activación de la memoria colectiva, inscribe ciertas características y relatos que sirven de vehículo para la construcción de una actitud crítica acerca del pasado; proceso complejo que anuda la subjetividad del visitante con la capacidad de narrar lo acontecido a través de la gestión de la memoria; es decir, a través de la aplicación de políticas de memoria que potencien los lugares seleccionados para la conmemoración.

Para Nora Rabotnikof, "la memoria y la conmemoración, y ambas reconocerían que son los intereses, las necesidades, los miedos y las ideas del presente los que dirigen la aproximación al pasado. Ambas afirmarían también que la conmemoración, como ejercicio de memoria colectiva, es una operación selectiva, que combina recuerdo y olvido. Pero la primera postura enfatizaría la continuidad, y en especial la continuidad identitaria de la comunidad o del grupo a través del tiempo. Por lo tanto, la función de los ritos conmemorativos no sería tanto transformar el pasado poniéndolo al servicio del presente, sino la de revivirlo tal cómo fue, reproducirlo, para reactualizar así el sentido de comunidad. El escenario de la conmemoración es la que refiere a la Nación, como referente simbólico unitario o unificador (Rabotnikof, 2009, p. 185).

Hoy, en Ayacucho, las numerosas convocatorias a la conmemoración de nuestro Bicentenario convocan a una visión plural del pasado, llaman a las múltiples historias que deben ser contadas (según las regiones, los grupos sociales, el género, la etnia, etc.) sobre la Independencia, pero sobre todo de la batalla de Ayacucho lograda en la misma pampa. Entonces, "reescribir la bistoria de bronce, hacerla más humana y adaptarla quizá a las nuevas condiciones del espacio público mediático" (Rabotnikof, 2009, p. 199), lo que haría que la continuidad de ese pasado histórico siga permanente en la memoria colectiva del ciudadano peruano.

El ceremonial conmemorativo que se lleva a cabo cada año en la pampa de Ayacucho, como "geografía de la memoria", adopta las formas rituales de dicha (re)memoración "sacra" de la naciente república peruana, donde se dan los despliegues de repiques de campanas, escenificaciones, desfiles, discursos y ceremonias. Por lo tanto, la fecha del 9 de diciembre se convierte en una coyuntura de activación de la memoria. La 
esfera pública es ocupada por la conmemoración, con manifestaciones compartidas (Jelin, 2002, p. 52), por los que asisten a la pampa de Ayacucho. Así, pues, "como instrumento poderoso y pedagógico para inculcar la historia patria y el culto a los héroes, se fomentó la celebración de ceremonias cívicas y la construcción de monumentos conmemorativos a los héroes. De esta manera, se intensificó la materialización de la memoria histórica en piedra y bronce, alimentada por los proyectos gubernamentales" (Zárate, 2010, p. 92); el "interés por mantener viva la imagen, las hazañas de aquellos personajes en el imaginario colectivo, se reflejó también n la celebración de los ritos sagrados de la nación en torno de monumentos públicos donde se depositan ofrendas ceremoniales. La liturgia de la conmemoración entendida como un ritual instituido-las procesiones cívicas y los desfiles patrióticos con sus himnos, estandartes y banderas, pueden catalogarse como procedimientos culturales que promueven y difunden la idea de nación, en tanto comunidad imaginada e imaginaria. Lo que nos enseña la ritualización de las conmemoraciones es que en estas se tejen formas elementales de sociabilidad en una comunidad, dado que el espectáculo y la cultura política que promueven, encierran formas tanto de persuasión como de coerción. De persuasión, cuando en la pompa de las ceremonias cívicas se crean espacios de unanimidad alrededor de símbolos, emblemas e imágenes de representación estatal. Y de coerción, en tanto que las conmemoraciones masivas permiten la puesta en escena de los imaginarios del poder. En suma, el despliegue de ceremonias, rituales conmemorativos y de héroes patrios se convirtió en la escenificación del "buen orden cívico", y su correcta lectura intelectual, moral y emocional convirtió a los asistentes (espectadores) en buenos ciudadanos. El control de los rituales por parte de los estados modernos es, por ende, una de las principales necesidades de este poder cuando los institucionaliza” (Brenes, 2005, pp. 113-114).

Finalmente, "la conmemoración es un ritual reconstructivo. Donde las ceremonias prueban, su carácter conmemorativo, en tanto, que son representaciones/actuaciones. Las ceremonias conmemorativas mantienen aspectos del pasado en el presente mediante representaciones descriptivas de hechos del pasado. Dichas conmemoraciones son reconstrucciones del pasado, el retorno de dicho pasado a través de representaciones que habitualmente incluyen simulacros de la escena revivida. Pro estas conmemoraciones, dependen también de la retórica de la persecución puesta en práctica durante la ceremonia y de la prescripción corporal y de comportamiento (Bolaños, 2010, p. 171) de quienes asisten a la pampa de Ayacucho.

(Re)memorar el pasado de la batalla de Ayacucho, ayuda a refrescar la "memoria colectiva" del poblador ayacuchano, que lo escucha a través de los discursos por la radio, televisión, y las redes sociales; y lo ve en los desfiles, ceremonias cívicas, escenificaciones, el propio Obelisco; etc donde todo el grupo social se identifica con el "lugar de memoria", como es la pampa de Ayacucho.

\section{CIERRE}

Sí la "geografía de la memoria" es localizar la historia y sus representaciones en el paisaje conmemorativo de la Pampa de Ayacucho, entonces, se hace necesario, que la mejor forma de respetar a los muertos es ayudarles a decir algo provechoso a los vivos. Necesitamos llevar a cabo una suerte de justicia histórica, no solamente historiográfica, 
sobre la batalla de Ayacucho y su Santuario Histórico Nacional, sino considerando la conmemoración y (re)memoración de dicho acontecimiento, como dice Steve Stern, "una representación que nos llega a través de los nudos convocantes de la memoria emblemática, (Stern, 1998).

En ese sentido, los actos públicos y conmemorativos son mecanismos que se implantan en la sociedad, para lograr colectivamente una lectura compartida de ese pasado, sobre la batalla de Ayacucho de 1824; donde el pueblo participa activamente en la fiesta cívica. De esta manera, "los gobernados, sienten que comparten un destino histórico común, el cual es memorizado, conmemorado y trasmitido mediante las ceremonias públicas masivas, los discursos, la entonación de los himnos y la sacralización de emblemas nacionales. El espectáculo desplegado en torno a la "lugares de la memoria", como la conmemoración. Se convierten en la representación del buen orden cívico" (Brenes, 2002, pp. 19-20). Entonces, siendo de esta manera, que la "geografía de la memoria" difunde año tras año, el 9 de diciembre, en ese paisaje emblemático de la Pampa de Ayacucho, los rituales de conmemoración que pasan de generación en generación; implantada, también, en la enseñanza de la historia patria en las escuelas y colegios del Perú.

La pampa de Ayacucho, dentro de la "geografía de la memoria", nos ha confirmado de como el Estado y la comunidad de notables, ha fortalecido el concepto de comunidad política imaginada, que es la nación peruana; siendo a la vez, los portavoces de dicha conmemoración emblemática.

Como lo que ocurrió, recientemente, en el 9 de diciembre del 2020, cuando el Presidente de la República, Francisco Sagasti, pronunció, que en esta histórica pampa, diciendo que aquí se selló la independencia definitiva del Perú y se consiguió la libertad; su discurso nos trasladó a este "paisaje de memoria", que al pronuncia dichas palabras, el público presente, se trasladó "imaginariamente" a esa fecha gloriosa del 9 de diciembre de 1824; simplemente, porque en su "memoria" aún pervive los pasaje de la batalla de Ayacucho y porque gracias a los difusores de dicha conmemoración hacen posible, que la sociedad, recuerde a sus "héroes", que sacrificaron su vida por darnos la independencia y que ahora, la "geografía de memoria", como un episodio emblemático que nunca se olvidará, sobre todo, en vísperas de su Bicentenario en el año 2024.

Nuestro Bicentenario, está cerca (2024); esperamos que nuestras autoridades nacionales y regionales, logre las obras públicas que Ayacucho necesita, para lograr su bienestar, en estos tiempos de pandemia, que azota nuestro Perú desde el 2020-2021. Tanto la Batalla como la pampa de Ayacucho, como símbolos de identidad nacional, sea el "caballito de batalla", que la región necesita para "arrancarle al Estado peruano, mayor presupuesto, para el progreso de nuestra región.

Sea, la oportunidad, para conocer como geógrafos e historiadores, pueden entrelazar interdisciplinariamente en la difusión de nuestra historia, tradición y cultura; recuperando la "geografía y lugares de memoria", para el conocimiento de la sociedad ayacuchana, que tanto lo necesita. 


\section{REFERENCIAS BIBLIOGRÁFICAS}

Allier, E. (2008) Los Lieux de mémoire: una propuesta historiográfica para el análisis de la memoria. En: Historia y Grafía, núm. 31. Distrito Federal, México.

Brenes, G. (2005) "Héroes y liturgias del poder: La ceremonia de la apoteosis. México, 6 de octubre de 1910". Revista de Ciencias Sociales. Vol. IV. N 106. Universidad de Costa Rica.

Brenes, G (2002) "La estatuaria cívica: El caso de Costa Rica. Siglos XIX y XX. Revista Ciencias Sociales. Vol. II. N 96. Costa Rica.

Dammert, A. \& Cusman, T. (1976) Ayacucho. La Libertad de América. 2da edición. Lima.

Díaz, D. (2007) Memoria colectiva y ceremonias conmemorativas. Una aproximación teórica. En: Diálogos Revista Electrónica de Historia, Vol. 7. № 2. Universidad de Costa Rica.

Fabri, S. (2013) "Lugares de memoria y marcación territorial: sobre la recuperación de los centros clandestinos de detención en Argentina y los lugares de memoria en España”. Cuadernos de Geografía - Revista Colombiana de Geografía, vol. 22, núm. 1, enero-junio. Universidad Nacional de Colombia. Bogotá, Colombia.

García, J (2009) lugares, paisajes y políticas de memoria: Un alectura geográfica. Boletín de la A.G.E. N 51. Universidad Carlos III. Madrid. España.

Hamann, J. (2011) Monumentos públicos en espacios urbanos de lima 1919-1930. Tesis doctoral. Universidad de Barcelona. España.

Jelín, E. (2002) Los trabajos de la memoria. Siglo veintiuno editores. España.

Nora, P. (2008) Les Lieux de mémoire. Quarto Gallimard. Ediciones Trilce. España.

Oliva, F. (1924) Apuntes para la historia de Huamanga o Ayacucho. Ayacucho.

Rabotnikof, N. (2009) Política y tiempo: Pensar la conmemoración. Cuaderno Sociohistórica, $\mathrm{N}^{\circ}$ 26. Universidad Autónoma de México. México.

Ruiz, J (1924) Monografía histórico-Geográfico del Departamento de Ayacucho. Imprenta Torre Aguirre. Lima.

Stern, S. (1998) De la memoria suelta a la memoria emblemática: Hacia el recordar y el olvido como proceso histórico (Chile, 1973-1998). Chile.

Vargas, R. (1974) Historia de las batallas de Junín y Ayacucho. Editorial Milla Batres. Lima.

Vásquez. J (2006) Identidad e Historia...La verdad sobre la historia batalla de Ayacucho de 1824. Ayacucho-Perú.

Viñuales, R. (2008) Monumento conmemorativo y espacio público en Iberoamérica. España.

Zárate, V (2010) “Los hitos e la memoria o los monumentos en el centenario de la Independencia de México. Ópera imaginaria en una obertura y tres actos. Revista. Mexicana $\mathrm{N}^{\circ}$ 1. México. 


\section{WEBGRAFÍA}

www.deconmemoraciones,memoriaseidentidades de Nora Rabotnikof recuperado: 15/02/2021.

\section{CITAR COMO:}

Oré Medina, J. J., \& Vásquez Gonzales, J. M. (2021). Paisaje, conmemoración emblemática, e identidad: La Pampa de Ayacucho, como "geografía de la memoria". Puriq, 3(3), 389-402. https://doi.org/10.37073/puriq.3.3.222 